\title{
Evaluating techniques for sampling stream crayfish (Paranephrops planifrons)
}

\section{CHARLES F. RABENI}

Missouri Cooperative Fish and Wildlife

Research Unit

Biological Resources Division

U.S. Geological Survey

112 Stephens Hall, University of Missouri

Columbia, Missouri 65211, United States

\section{KEVIN J. COLLIER}

\section{STEPHANIE M. PARKYN}

National Institute of Water \& Atmospheric

Research Ltd

P. O. Box 11115

Hamilton, New Zealand

\section{BRENDAN J. HICKS}

Department of Biological Sciences

University of Waikato

Private Bag 3105

Hamilton, New Zealand

\begin{abstract}
We evaluated several capture and analysis techniques for estimating abundance and size structure of freshwater crayfish (Paranephrops planifrons) (koura) from a forested North Island, New Zealand stream to provide a methodological basis for future population studies. Direct observation at night and collecting with baited traps were not considered useful. A quadrat sampler was highly biased toward collecting small individuals. Handnetting at night and estimating abundances using the depletion method were not as efficient as handnetting on different dates and analysing by a mark-recapture technique. Electrofishing was effective in collecting koura from different habitats and resulted in the highest abundance estimates, and mark-recapture estimates appeared to be more precise than depletion estimates, especially if multiple recaptures were made. Handnetting
\end{abstract}

M97007

Received 11 March 1997; accepted 21 July 1977 captured more large crayfish relative to electrofishing or the quadrat sampler.

Keywords crayfish; population structure; depletion; mark-recapture; electrofishing; New Zealand

\section{INTRODUCTION}

Recent studies have shown that freshwater crayfish can influence stream ecosystem processes such as sediment accumulation and organic matter processing and invertebrate community structure (e.g., Huryn \& Wallace 1987; Creed 1994; Parkyn et al. 1997). Although the ecological importance of crayfish in aquatic ecosystems is becoming more evident (Lodge \& Hill 1994; Momot 1995), our ability to adequately assess important population characteristics, e.g., density or size structure, remains suspect. Stream-dwelling crayfish have been sampled in a variety of ways, and biases are known for some techniques but not for all (DiStefano 1993). For example, baited traps are widely used for many North American generaOrconectes, Cambarus, and Pasifasticus-but favour the collection of larger males in the population (Mason 1975; Capelli \& Magnuson 1983; Olsen et al. 1991). Electrofishing may be inappropriate for areas with heavy brush cover where crayfish are inaccessible (Westman et al. 1978), whereas hand collections are restricted to situations of good visibility and may be subject to variable escapement (Roell \& Orth 1992). Seining is restricted to habitats without obstructions (Brant 1974), as are quadrat benthic samplers (Rabeni 1985).

Because accurate determination of population characteristics is a requirement for many ecological studies on crayfish, it is important to know the limitations of sampling methods. In New Zealand, published work on stream-dwelling crayfish Paranephrops spp. (koura) has focused on growth, breeding, and behaviour (Hopkins 1966, 1967; Shave et al. 1994) where both handnetting and electrofishing sampling were used but for objectives 
where sampling biases were not important. Little is known of the abundance or population characteristics of lotic freshwater koura, perhaps partly because they are not easity collected using conventional benthic invertebrate sampling techniques.

The objective of this study was to assess the relative usefulness of a number of sampling techniques in estimating the population size structure and density of a population of $P$. planifrons from a North Island, New Zealand stream. This study is unique because it estimates population characteristics of crayfish in the same system using different methods.

\section{STUDY AREA}

The study area was on Firewood Creek located in the Ngaruawahia Forest northwest of Hamilton, North Island, New Zealand (NZMS260 map reference S 14976888 ). The site was $40 \mathrm{~m}$ a.s.l. and had an up-stream catchment area of $2.01 \mathrm{~km}^{2}$. The site was heavily shaded by vegetation (diffuse noninterceptance radiation $=0.016$ ), and mean water temperature over the early summer (NovemberDecember) averages $12.5^{\circ} \mathrm{C}$ (Smith et al. 1993; NIWA unpubl. data). Riparian vegetation was predominantly nikau (Rhopalostylis sapida), ferns (Dicksonia, Cyathea, and Blechnum spp.), and parataniwha (Elatostema rugosum) beneath a mixed forest overstory which included tawa (Beilschmieda tawa), rimu (Dacrydium cupressinium), and rewarewa (Knightia excelsa).

The study site consisted of three contiguous reaches: an up-stream reach c. $17 \mathrm{~m}$ in length, a middle section $14 \mathrm{~m}$ long, and a lower section 11 $\mathrm{m}$ long. The site was chosen because of its physical complexity and was composed on an areal basis of c. $21 \%$ dammed pool, $20 \%$ lateral scour pool, $4 \%$ undercut bank, $28 \%$ run, $24 \%$ riffle, and $4 \%$ side channel (see Bisson et al. 1982 for definitions of habitats). The site averaged $2.9 \mathrm{~m}$ in width $(\mathrm{SD}=$ 0.9 ) with a range of $0.9-4.6 \mathrm{~m}$. Current velocities at the water surface, taken during quadrat sampling, ranged from $<10$ to a little over $30 \mathrm{~cm} \mathrm{~s}^{-1}$. Depths ranged from a few centimetres in riffles to $\mathrm{c} .40 \mathrm{~cm}$ in pools.

\section{METHODS}

The experimental design allowed for a variety of sampling techniques and analyses. Three contiguous reaches were sampled on all but one date with multiple passes through each reach. We were able to estimate abundance by direct count (both observation and handnetting), depletion, and single and multiple recapture methods. Size-frequency comparisons among methods were used to examine equipment biases, and we examined overall differences in the size distribution of koura caught by handnetting, electrofishing, and quadrat sampling.

Abundance estimates were made by direct observation and handnetting on consecutive evenings (between 2100 and $0100 \mathrm{~h}$ NZST) on 30 and 31 January 1996. Handnetting consisted of direct stalking of koura during darkness with the aid of hand-held torches and helmet-mounted lights. Generally, two people would start at the downstream end of each of the three reaches and work slowly up-stream for c. $20 \mathrm{~min}$, netting all observed koura. This was sufficient time to carefully examine all parts of the reach, and was termed a "pass". After c. $10 \mathrm{~min}$ the next pass was begun, which allowed c. $30 \mathrm{~min}$ between observations at any one place in the stream. Generally, three passes were conducted in each reach. Direct observation was the number of koura observed on the first pass of the handnetting operation, as observing during multiple runs would undoubtedly recount individuals. The observation period was c. $2 \mathrm{~min} \mathrm{~m}^{-2}$ of substrate surface, and was considered more than sufficient to detect any exposed crayfish.

Electrofishing consisted of using a back-pack electrofishing unit, battery operated on 1 February and gasoline powered on 22 February, to slowly examine all of the wetted perimeter during daytime

Table 1 Schedule of sampling, sampling method, and type of analysis used to estimate abundance of stream crayfish (Paranephrops planifrons) (koura) in 1996.

\begin{tabular}{|c|c|c|}
\hline Date & Method & Analysis \\
\hline $30 \mathrm{Jan}$ & $\begin{array}{l}\text { Handnetting } \\
\text { Observation }\end{array}$ & Depletion, direct count \\
\hline \multirow[t]{2}{*}{31 Jan } & Handnetting & $\begin{array}{l}\text { Depletion, mark- } \\
\text { recapture }\end{array}$ \\
\hline & Observation & \\
\hline 1 Feb & Electrofishing & $\begin{array}{l}\text { Depletion, multiple } \\
\text { mark-recapture }\end{array}$ \\
\hline I Feb & Handnetting & $\begin{array}{l}\text { Check on electro- } \\
\text { fishing }\end{array}$ \\
\hline $5 \mathrm{Feb}$ & Quadrat sampler & Direct estimates \\
\hline 22 Feb & Electrofishing $\dagger$ & $\begin{array}{l}\text { Depletion, multiple } \\
\text { mark-recapture }\end{array}$ \\
\hline
\end{tabular}

†Middle reach only. 
(Table 1). A shocker and a netter would work together, while directly down stream a person with a small seine captured any drifting koura. On 1 February, two electrofishing passes of the entire study site were made, whereas on 22 February five passes of the middle reach only were made to evaluate the precision of the depletion electrofishing technique. Koura collected on 1 February were held outside the stream in buckets, and on the same evening handnetting similar to that conducted on 30 and 31 January was done to obtain a conservative estimate of crayfish not collected by electrofishing.

A quadrat sampler was used to obtain direct estimates of koura abundance in the substrate. The sampler consisted of a metal frame enclosing a $0.5 \mathrm{~m}^{2}$ area $(1 \times 0.5 \mathrm{~m}$ rectangle, $0.4 \mathrm{~m}$ high $)$ and had four legs $(0.1 \mathrm{~m}$ long) which were worked into the substrate. The sampler was surrounded on three sides by $3-\mathrm{mm}$ netting with the bottom weighted by a chain, and had a $1-\mathrm{mm}$ mesh net on the downstream end. It was operated in a manner similar to that of a Surber bottom sampler, where the sampler was laid on the substrate and the substrate within disturbed by hand. Koura were carried into the collection bag by natural or operator-induced current. Ten quadrat samples were taken during the daytime of 5 February.

A wire-mesh trap baited with dog biscuits or sheep liver was tried but found to be ineffectual in capturing $P$. planifrons. This method was abandoned.

Regardless of collection method, collected individuals were placed in buckets or chilly bins alongside the stream. Each koura was measured (from the posterior border of the eye-socket to the mid-dorsal posterior border of the carapace (Hopkins 1966), referred to hereafter as carapace length (CL)) to the nearest millimetre using vernier calipers. The edge of the telson fin was clipped to distinguish the date or method of collection and koura were released near the point of capture. Telson fins of koura $<5 \mathrm{~mm}$ CL were too small to be clipped.

Population estimates were calculated three ways. For estimates from a single visit to a site we used the removal method which, by using catches of animals from repeated standardised catch effort, regresses the catch-per-effort on the cumulative number of animals removed. The estimated population size is the cumulative catch for which the expected catch-per-effort is zero, which is the $x$-intercept (Zippin 1958). For two or more sampling visits to a site capture-recapture methods were used.
Captured animals were uniquely marked and on the second and subsequent collections the proportion of unmarked animals and the recapture of marked animals were used to estimate population abundance. The Chapman modification of the Peterson Index was used for single recaptures and the Schnabel method used for multiple recaptures (Ricker 1975).

\section{RESULTS}

\section{Population estimates}

\section{Direct observations and handnetting}

Direct observation in the three reaches combined resulted in a total counting of $43\left(0.35 \mathrm{koura} \mathrm{m}^{-2}\right)$ individuals the first night and $31\left(0.25 \mathrm{~m}^{-2}\right)$ the second night. Four passes with handnets and subsequent analysis of all koura collected by the Zippin depletion method (Zippin 1958) resulted in abundance estimates of 96 and $89(0.79$ and 0.73 $\mathrm{m}^{-2}$, respectively) koura each night. Both estimates had impressively tight $95 \%$ confidence intervals of about $\pm 10 \%$ of the mean.

Because the 30 January captures were marked with a telson clip, an abundance estimate of koura $>5 \mathrm{~mm} \mathrm{CL}$ was possible from the 31 January collection using mark-recapture analysis. An estimate of total abundance was also made by adjusting for small individuals that could not be marked by using a correction factor of $12 \%$ which was the mean percentage of koura $<5 \mathrm{~mm}$ from all collections except the quadrat collections. This corrected estimate (Fig. 1) does not have an associated variance.

Using the Chapman modification of the Peterson method (Ricker 1975) an abundance estimate of 274 koura ( $>5 \mathrm{~mm} \mathrm{CL} ; 2.25 \mathrm{~m}^{-2}$ ) with a $95 \%$ confidence interval of 175-373 was obtained (Fig. 1). An estimate of total abundance was also made by adjusting for small individuals that could not be marked. This corrected estimate $\left(306 ; 2.51 \mathrm{~m}^{-2}\right)$ does not have an associated variance. Thus, the estimated abundance from direct observation was about half the number actually collected by handnetting, and for handnetted crayfish the markrecapture estimate was about two and a half times greater than the depletion estimate (Fig. 1).

\section{Electrofishing}

Two capture runs with the electrofisher on 1 February enabled an analysis by the depletion method (Zippin 1958), and resulted in an estimate 


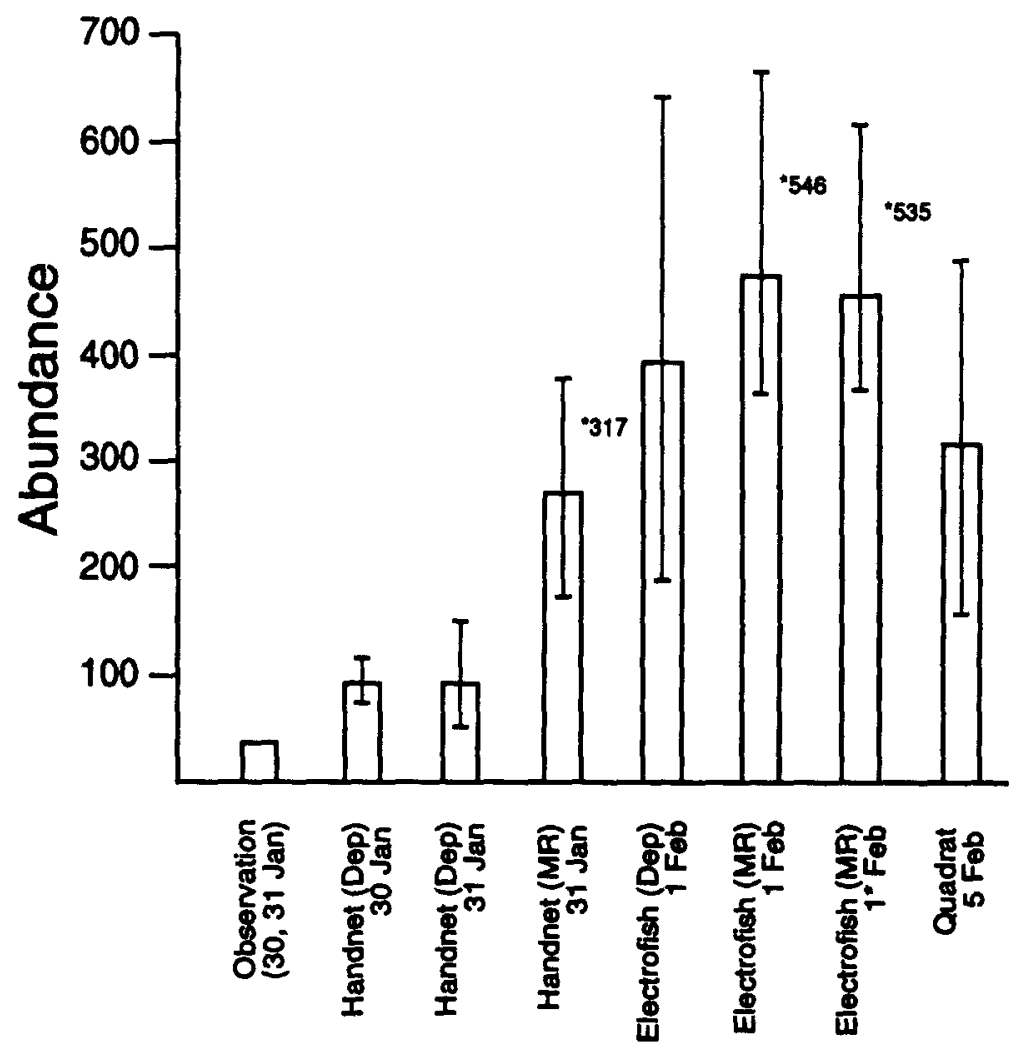

Fig. 1 Freshwater crayfish (Paranephrops planifrons) (koura) abundance estimates with $95 \%$ confidence intervals for all sampling dates, methods, and analyses. Numbers with an $\left({ }^{*}\right)$ are abundance estimates adjusted for very small $(<5 \mathrm{~mm}$ in length) individuals. Data of 1 February include koura collected by handnetting subsequent to electrofishing. $($ Dep $=$ depletion estimate; $\mathrm{MR}=$ mark-recapture.)

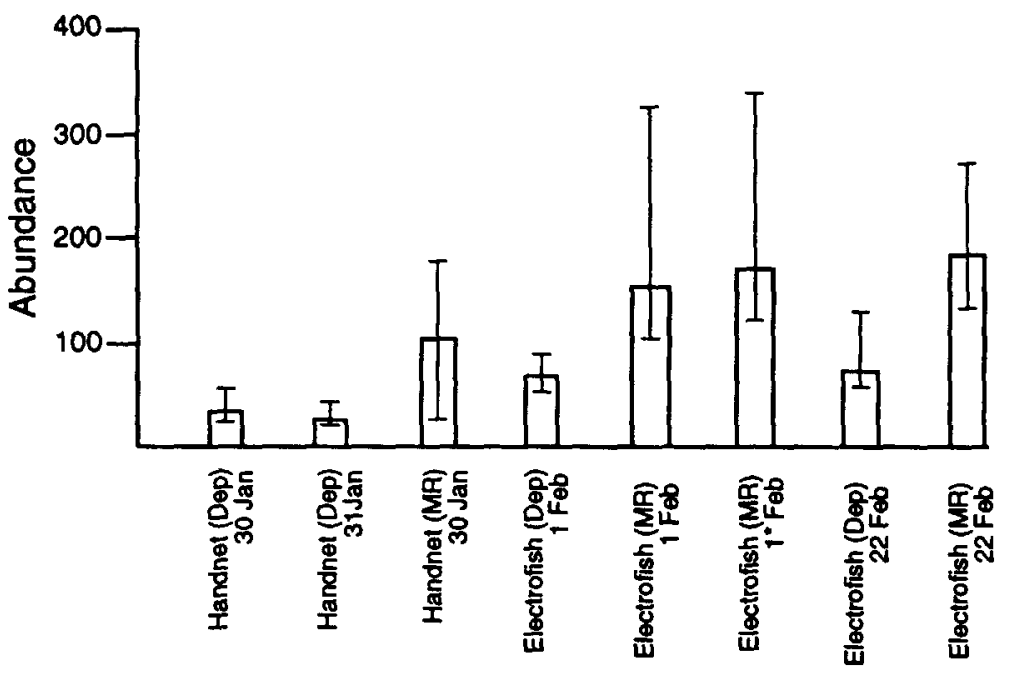

Fìg. 2 Freshwater crayfish (Paranephrops planifrons) (koura) abundance estimates with $95 \%$ confidence intervals from the middle reach of the study site using various sampling and population estimation techniques. (Dep = depletion estimate; $M R=$ mark-recapture.)

of 400 individuals in the site with fairly wide $95 \%$ confidence intervals of about $\pm 50 \%$ of the mean (Fig. 1).

A mark-recapture abundance estimate was made on the 1 February electrofishing collection, analysed by the Schnabel multiple recapture technique
(Ricker 1975) using marked individuals from both handnetting nights. This resulted in an estimate of $471\left(3.86 \mathrm{~m}^{-2}\right)$ with a $95 \%$ confidence interval of $370-647$ (Fig. 1). The $12 \%$ correction for very small crayfish raised the total site estimate to 527 $\left(4.32 \mathrm{~m}^{-2}\right)$. 
Handnetting on the evening of 1 February resulted in the collection of an additional 30 crayfish which, by depletion analysis, indicated that 54 animals remained in the stream after electrofishing. Fifty-four additional crayfish gives a total well within the previously determined confidence interval. By incorporating the 1 February handnetted catch of marked and unmarked individuals into the mark-recapture calculations the abundance estimate becomes $461\left(3.78 \mathrm{~m}^{-2}\right)$. This is similar to the estimate when using only electrofishing recaptures $471\left(3.86 \mathrm{~m}^{-2}\right)$ but with a somewhat tighter $95 \%$ confidence interval (Fig. 1).

\section{Quadrat sampling}

This technique yielded a mean of 1.4 individuals per sample with a standard deviation of 1.3. This represents a site abundance estimate of 317 with a $95 \%$ confidence interval of about $\pm 50 \%$ of the mean.

On 22 February five electrofishing passes were made on the middle reach ( $14 \mathrm{~m}$ long; $37.4 \mathrm{~m}^{2}$ ) of the study area (Fig. 2). The abundance estimate of 79 individuals $\left(2.11 \mathrm{~m}^{-2}\right)$ made by the depletion method (Zippin 1958) was similar to the 1 February estimate $\left(68 ; 1.81 \mathrm{~m}^{-2}\right)$ whereas 22 February Schnabel mark recapture estimate, using all previously marked individuals was not very different from the 1 February Schnabel estimate of $181\left(4.83 \mathrm{~m}^{-2}\right)$ but it possessed a smaller $95 \%$ confidence interval (Fig. 2).

\section{Size-frequency analysis}

Collections using the quadrat sampler were dominated by more smaller individuals than were collections from the other two sampling methods. Fifty-seven percent of all individuals collected with this device were in the 3-6 mm CL size range $(X=$ $5.8 \mathrm{~mm} \mathrm{CL}$ ), and none were over $15 \mathrm{~mm} \mathrm{CL}$.

The size structures of $P$. planifrons collected by electrofishing and handnetting were more similar to each other than to collections made with the quadrat sampler (Fig. 3) and were not dominated by small individuals. Whereas there was an identical modal size range of 6-9 $\mathrm{mm} \mathrm{CL}$, handnetting captured a relatively greater proportion of mid-sized individuals (those between 12 and $18 \mathrm{~mm} \mathrm{CL}$ ); electrofishing captured a greater proportion of smaller crayfish $(<9 \mathrm{~mm} \mathrm{CL}$ ). The mean size captured by handnetting was $13.6 \mathrm{~mm} \mathrm{CL}$, whereas the mean size captured by electrofishing was $10.4 \mathrm{~mm} \mathrm{CL}$.

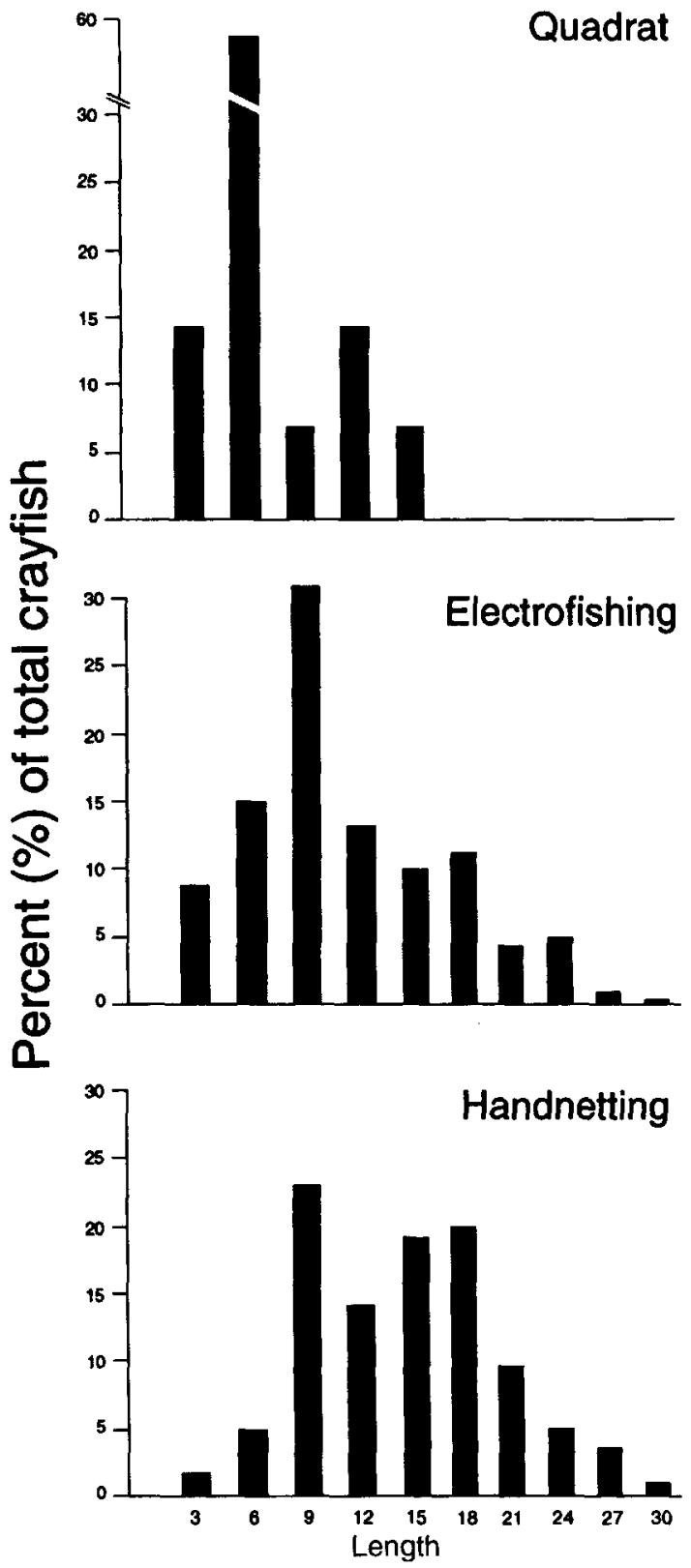

Fig. 3 Carapace length-frequency distributions (mm) of freshwater crayfish (Paranephrops planifrons) (koura) captured by three methods.

The biases resulting in larger crayfish being captured by handnetting relative to electrofishing were also evident on 1 February when the site was electrofished and then handnetted before the individuals collected by electrofishing were returned to the stream (Fig. 4). Handnetting again 


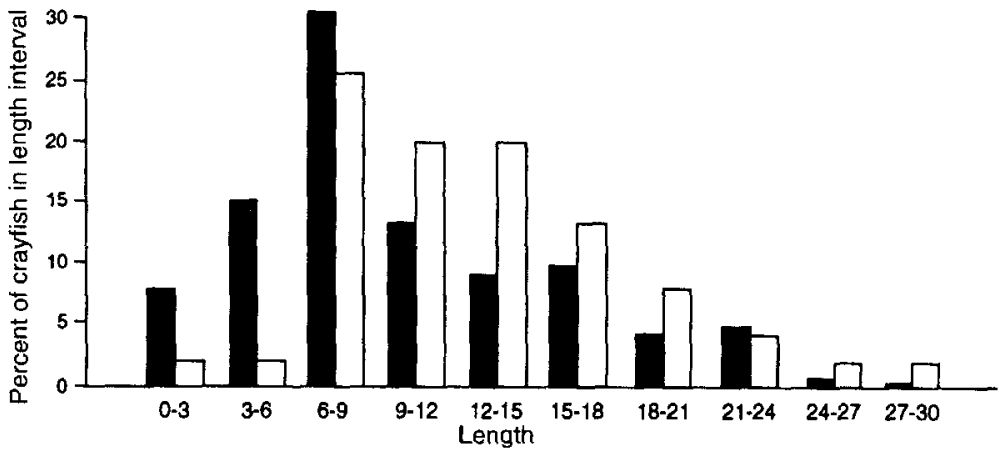

Fig. 4 Carapace lengthfrequency distributions (mm) of freshwater crayfish (Paranephrops planifrons) (koura) captured by electrofishing on 1 February (dark bars), and a subsequent collection by handnetting (light bars).

captured a relatively greater proportion of larger koura in the 12 and $15 \mathrm{~mm} \mathrm{Cl}$ size groups. The mean size collected by electrofishing, $10.4 \mathrm{~mm}$, was substantially smaller than the handnetted mean size of $13.0 \mathrm{~mm}$.

What could not be determined was whether the differences in mean size were a result of handnetting collecting relatively greater numbers of mid-sized individuals or relatively fewer smaller individuals, or whether electrofishing caught relatively greater numbers of small (6-9 $\mathrm{mm} \mathrm{CL}$ size class) individuals.

We investigated whether vulnerability to capture was related to size when repeated captures were involved. No evidence of this was found. On 22 February the five electrofishing runs showed some variation in the mean size of individuals from first to last pass of $16.6,13.1,12.9,17.4$, and $11.1 \mathrm{~mm}$. The total captures from each of the two electrofishing runs on 1 February showed little difference in mean size of individuals between the first $(10.9 \mathrm{~mm})$ and second $(9.7 \mathrm{~mm})$ passes.

\section{DISCUSSION}

Studies of population dynamics and production of Paranephrops spp. and other crayfishes in streams require knowledge of densities and year-class composition with some degree of confidence. Such confidence may be difficult to obtain, especially with relatively low-density populations. As a general rule, the greater the density or abundance of the population, the easier it is to achieve a particular level of precision. Low-density populations require relatively high captures for depletion methods and high captures and recaptures for mark-recapture methods.

Assuming our study site contained 500 individuals $\left(4 \mathrm{~m}^{-2}\right)$, over three-quarters of the population needed to be captured to be within $10 \%$ of the true population size with $90 \%$ probability using either removal or mark-recapture methods (Zippin 1958; Robson \& Regier 1964). This level of precision is probably not realistic for stream koura regardless of sampling intensity. A more realistic goal often used in research studies with invertebrates is a precision of within $20 \%$ of the true population size (Elliott 1971; Cummins 1975). This would require capturing roughly half of the population, which appears to be an attainable goal in situations such as ours if multiple collections are made.

A consequence of the rather wide variance associated with our estimates is that it becomes more difficult to detect statistically significant differences between populations or in a population over time. To detect a significant change in densities (defined as non-overlapping $95 \%$ confidence intervals) using the multiple mark-recapture sampling estimate which ended on 1 February would require a difference in means (increase or decrease) of c. $60 \%$.

Equally important as precision of abundance estimates is the question of gear size selectivity. Length-frequency distributions are commonly used in studies of crayfish and other decapods to delineate age groups (France et al. 1991), and errors at this stage of the study can influence evaluations of many aspects of population dynamics. Investigators not able to quantify their populations often are content to obtain a "representative" qualitative sample. However, a sampler unable to collect a quantitative sample probably is also size selective, so the results of even qualitative samples should be questioned - especially if they are used to evaluate population characteristics such as age distribution (e.g., France et al. 1991) or mortality.

An important assumption for use of markrecapture methods is that immigration or emigration during the study was negligible (Robson \& Regier 
1964). If random or directional movements occurred unmarked individuals would enter the study area while marked and unmarked animals would exit. The number of marked individuals in the population, and therefore the percentage of marked individuals would also decrease. We conclude that immigration and emigration were not significant because the percentage of marked individuals captured as a percentage of total available marked individuals actually increased over time from the second to last sampling in both the total site and in the middle site estimates.

Another possible cause of error is that the marked individuals were not equally susceptible to recapture as unmarked individuals (Robson \& Regier 1964). P. planifrons may "learn" to avoid capture on subsequent exposure to the collector. Less vulnerable animals will result in underestimation of abundances using depletion techniques and overestimation of abundances using mark-recapture techniques. Similar errors would result if captured koura suffered some mortality because of handling and telson clipping, or if electrofishing amplified the flexing of the telson muscles of freshly molted crayfish to cause muscle detachment. However, no mortality was observed when numerous koura were held in buckets for several hours after electrofishing and marking on 1 February.

Certainly the effectiveness of any technique is dependent upon habitat conditions and the behaviour of the organisms. $P$. planifrons of our stream were exposed outside of protective cover only at night. Depletion estimates may be low because the entire population was not vulnerable to capture on any one collection date. Boulders, undercut banks, and tangles of root material, where $P$. planifrons appear to spend extended periods of time during the day, offer potential refugia from being collected by some techniques. Only electrofishing appeared effective in heavy cover, where increased activity of the affected animals made them visible and susceptible to netting in slow-current areas and being carried into a seine in fast-current areas.

\section{CONCLUSIONS AND RECOMMENDATIONS}

Although the true density and age structure of this population remains unknown our multiple gear approach allows us to infer inherent biases of each method. We captured 296 different individuals $>0.5$ $\mathrm{mm} \mathrm{CL}$ and at least 40 different smaller koura giving a total of $343\left(2.81 \mathrm{~m}^{-2}\right)$ which is a minimum estimate of the population. The direct censusing obviously severely underestimated abundances, could not be used for size analysis, and should not be considered further. The method was attempted because in some situations it is thought to be the most accurate method to obtain population information about crayfish (Lamontagne \& Rasmussen 1993). Handnetting depletion gave a precise (i.e., tight confidence interval) estimate, but also greatly underestimated abundances. It was revealing how it was possible to obtain quite small confidence intervals using a particular technique even though the technique was highly biased. Handnetting appears to capture relatively more larger individuals than any of the other methods; either larger crayfish are observed more readily, or larger crayfish are more active and exposed at night. We recommend handnetting for abundance estimates only in conjunction with a second capture method in capture-recapture efforts.

The quadrat sampler captured relatively more smaller individuals than the other methods. Although $16 \%$ of captures from all other methods over the course of the study were $<5 \mathrm{~mm} \mathrm{CL}$, the quadrat sampler collected $81 \%$ of its total in this approximate size range. Handnetting collected relatively more larger individuals than the other methods. Density estimates from quadrat sampling, although similar to multiple mark recapture estimates, are not really comparable because the quadrat sampler captured such a high percentage of very small individuals. The quadrat sampler can be used to investigate young-of-year koura in appropriate habitats, but we do not recommend any of the techniques for quantitatively sampling very small individuals throughout a stream.

Electrofishing was considered the most accurate sampling tool in this study. Electrofishing depletion gave a 2-4 times greater abundance estimate than the handnetting method, and was comparable to mark-recapture estimates using electrofishing as the recapture technique. Multiple mark-recapture is preferable to single mark-recapture as it substantially reduces variance. Marking animals collected by one method and recapturing by another is preferable to using one method throughout.

\section{ACKNOWLEDGMENTS}

Our thanks to David West and Helen McCaughan who assisted with the electrofishing. Liz Halsey, Paul Johnson, 
and Jane Rabeni assisted with field work. Greg Whitledge, University of Missouri, assisted with the analyses. This is a contribution from the Missouri Cooperative Fish and Wildlife Research Unit (Biological Resources Division, U.S. Geological Survey; Missouri Department of Conservation; University of Missouri; and Wildlife Management Institute cooperating).

\section{REFERENCES}

Bisson, P. A.; Nielsen, J. L.; Palmason, R. A.; Grove, L. E. 1982: A system of naming habitat types in small streams, with examples of habitat utilization by salmonids during low streamflow. Pp. 62-73 in: Proceedings of the Symposium on Acquisition and Utilization of Aquatic Habitat Inventory Information. Armandtrout, N. B. ed. Portland, Oregon, Western Division of the American Fisheries Society.

Brant, T. M. 1974: Effects of harvesting aquatic bait species from a small West Virginia Stream (part 1) and crayfish marking with fluorescent pigment (part 2). Unpublished MS thesis, Virginia Polytechnic Inștitute and State Uńiversity, Blacksburg, Virginia, United States.

Capelli, G. M.; Magnuson, J. J. 1983: Morphoedaphic and biogeographic analysis of crayfish distribution in northern Wisconsin. Journal of crustacean biology 3: 548-564.

Creed, R. P. 1994: Direct and indirect effects of crayfish grazing in a stream community. Ecology 75 : 2091-2103.

Cummins, K. W. 1975: Macroinvertebrates. Pp.170-199 in: River ecology. Whitton, B. A. ed. Berkeley, California, University of California Press.

DiStefano, R. J. 1993: Ecology of stream-dwelling crayfish populations: a literature review. Missouri Department of Conservation, Dingell-Johnson Project F-1R-42, Study S-41 Job 1, Final Report.

Elliott, J. M. 1971: Some methods of statistical analysis of samples of benthic invertebrates. Science publication no. 25, Freshwater Biological Association. 144 p.

France, R. L.; Holmes, J.; Lynch, A. 1991 : Use of sizefrequency data to estimate the age composition of crayfish populations. Canadian journal of fisheries and aquatic sciences 48: 2324-2332.

Hopkins, C. L. 1966: Growth in the freshwater crayfish, Paranephrops planifrons White. New Zealand journal of science 9: 50-56.

Hopkins, C. L. 1967: Breeding in the freshwater crayfish Paranephrops planifrons White. New Zealand journal of marine and freshwater research 1 : 51-81.

Huryn, A. D.; Wallace, J. B. 1987: Production and litter processing by crayfish in an Appalachian stream. Freshwater biology 18: 277-286.
Lamontagne, S.; Rasmussen, J. B. 1993: Estimating crayfish density in lakes using quadrats: maximizing precision and efficiency. Canadian journal of fisheries and aquatic sciences 50 : 623-626.

Lodge, D. M.; Hill, A. M. 1994: Factors governing species composition, population size and productivity of cool-water crayfish. Nordic journal of freshwater research 69: 111-136.

Mason, J. C. 1975: Crayfish production in a small woodland stream. Freshwater crayfish 2: 449-478.

Momot, W. T. 1995: Redefining the role of crayfish in aquatic ecosystems. Review of fisheries science 3: 33-63.

Olsen, T. M.; Lodge. D. M.; Capelli. G. M.; Houlihan, R. J. 1991: Mechanisms of impact of an introduced crayfish (Orconectes rusticus) on littoral congeners, snails, and macrophytes. Canadian journal of fisheries and aquatic sciences 48: 1853-1861.

Parkyn, S. M.; Rabeni, C. F.; Collier, K. J. 1997: Effects of crayfish (Paranephrops planifrons: Parastacidae) on in-stream processes and benthic faunas: a density manipulation experiment. New Zealand journal of marine and freshwater research 31: 685-692.

Rabeni, C. F. 1985: Resource partitioning by streamdwelling crayfish: the influence of body size. The American Midland naturalist 113: 20-29.

Ricker, W. E. 1975: Computation and interpretation of biological statistics of fish populations. Bulletin of the Fisheries Research Board of Canada 191. Ottawa.

Robson, D. S.; Regier, H. A. 1964: Sample size in Peterson mark-recapture experiments. Transactions of the American Fisheries Society 93: 215-226.

Roell, M. J.; Orth, D. J. 1992: Production of three crayfish populations in the New River of West Virginia, USA. Hydrobiologia 228: 185-194.

Shave, C. R.; Townsend, C. R.; Crowl, T. A. 1994: Antipredator behaviours of a freshwater crayfish (Paranephrops zealandicus) to a native and an introduced predator. New Zealand journal of ecology 18: 1-10.

Smith, M. J.; Cooper, A. B.; Quinn, J. M. 1993: Landwater interactions research at Whatawhata-the start. NIWA ecosystems publication no. 4, July 1993.

Westman, K.; Sumari, O.; Puriainen, M. 1978: Electric fishing in sampling crayfish. Freshwater crayfish 4: $251-256$.

Zippin, C. 1958: The removal method of population estimation. Journal of wildlife management 22 : 82-90. 